\title{
RENAL ARTERY MORPHOLOGY AND ANATOMICAL VARIATIONS AMONG SUDANESE SUBJECTS
}

Mugahid A Salih *(MBBS, MRCSed, MSc ,MD), Mohamed A Hasan (MS, FRCSI)

Correspondence to: Dr. Mugahid Salih, Department of Anatomy, Faculty of Medicine, University of Khartoum. E mail: juhjuh2003@hotmail.com.

\begin{abstract}
The objectives of this study were to determine the level of origin of the renal artery on both sides of the body, to describe its course and branching pattern on both sides, and to detect the Supernumerary renal arteries (SRA) and their course. Both cadaveric and radiological descriptive studies were conducted from July 2015 to July 2016.The morphology and variations of the renal arteries were documented in 50 formalin fixed cadavers that were dissected in different faculties of medicine in Khartoum state. This was followed by assessment of 150 computerized tomography angiographies of the renal transplant donors who presented to three major transplant centers in Khartoum in the period between 2012 and 2015. The most common vertebral level of origin off the aorta was between the first and second lumbar segments. A supernumerary renal artery was detected in $25.5 \%$ and it was the most common anatomical variation. This was followed by early prehilar bifurcation in $6.5 \%$. Supernumerary renal arteries were commonly hilar and lower polar, and they were more frequent in males. Bilateral supernumerary arteries were found in $4 \%$ of cases. The most common anatomical variation of the renal artery was supernumerary renal artery.
\end{abstract}

Key Words: Renal artery, supernumerary, anatomical variations.

\section{INTRODUCTION}

Because of the rising frequency of renal disorders, and the increasing demand for renal transplants, the need for a research aimed at a better knowledge of the variations of the renal blood vessels arose. The presence of accessory renal arteries may result in technical difficulties during renal transplantation (Alp et al., 2003).

On one hand, damage to any of the branches of the renal artery, regardless of its origin or destination will lead to necrosis of the corresponding renal parenchyma and may subsequently lead to renal hypertension. On the other hand, Selective renal arterial clipping or ligation, particularly of the presegmental and lower polar segmental arteries, may allow laparoscopic partial nephrectomy to be performed with minimal ischemic risk to the rest of the renal tissue (Sampaio and Passos, 1992).
Awareness of the possible anatomical variations of renal arteries is mandatory for surgical management during renal transplantation, assessment of reno- vascular hypertension, repair of abdominal aorta aneurysm, urological procedures and angiographic interventions. These procedures are being performed commonly nowadays, thus more knowledge of the anatomical variations of the renal artery in different populations is becoming crucial (Virendra et al., 2010). Since there are few data regarding renal artery variations among Sudanese population, this study investigated the morphology and branching pattern of the renal artery and the prevalence of additional renal arteries in Sudanese Subjects. Results could be compared with studies in other parts of the world and may be useful to surgeons, radiologists and interventional radiologists. 


\section{MATERIALS AND METHODS}

Both cadaveric and radiological descriptive studies were conducted from July 2015 to July 2016. Both were approved by the ethical committee of the Faculty of Medicine University of Khartoum. The morphology and variations of the renal arteries were documented in 50 formalin fixed cadavers that were dissected in different faculties of medicine in Khartoum state. They included: (Faculty of MedicineUniversity of Khartoum, Khartoum College of Medical Science, Al-Ribat National University, University of Science and Technology, Omdurman Islamic University and International Islamic University of Africa). The study included both Males and females above 18 years, and Intact formalin fixed cadavers suitable for abdominal dissection or already dissected cadavers with intact posterior abdominal wall. Cadavers with disturbed anatomy at the posterior abdominal wall and those with renal trauma were excluded. Abdominal dissection was conducted through a midline incision and during the course of dissection, abdominal viscera were retracted to reach the posterior abdominal wall. Kidneys along with their arteries were explored. The course, branching pattern and morphological variations of the renal arteries were then noted and supernumerary renal arteries were carefully detected if present and their course was established. The data was collected in a close ended questionnaire. This was followed by assessment of 150 CTangiographies of the renal transplant donors who presented to three major transplant centers in Khartoum in the period between 2012 and 2015.Questionnaires were filled by the data collected from the films of those donors who presented to Ibn Seena and Sharg Al -Neel Hospitals in Khartoum, and Ahmed Gasim Hospital in Khartoum North. Patients with renal disorders were excluded. The variables included the age, gender, nationality, renal artery origin, morphology, course, branching pattern and anatomical variations. All the participants were consented to leave their images for the purpose of research. The data was then analyzed using Statistical Package for the Social Sciences (SPSS) computer software and using statistical descriptive method.
Cadaveric $(n=50)$

Prehilar branching was the predominant one on both the right and left sides. It occurred in $46 \%$ and $64 \%$ respectively. This was followed by hilar branching (34\% on the right side and $20 \%$ on the left side) and intra-parenchymal parenchymal branching ( $20 \%$ on the right side and $16 \%$ on the left side). No vessel on the right side bifurcated at less than $15 \mathrm{~mm}$ (from its aortic origin), compared to five arteries on the left side $(10 \%)$ that showed very early bifurcation.

The pattern of the branching on the right side was bifurcation in $80 \%$ and trifurcation in $20 \%$. This was comparable to the left side, where bifurcation occurred in $85 \%$ and trifurcation in $15 \%$.

\section{RESULTS}

The most common anatomical variation was the presence of supernumerary renal artery(SRA), which was found in eleven bodies (22\%). Out of fifteen supernumerary arteries, nine were on the right side and six were on the left side. Figure 1 shows a SRA on the left side and figure 2 shows another one on the right side.

While only one SRA was superior polar (7.1\%), four were inferior polar $(28.5 \%)$ and ten were hilar (64.4\%). The course of the supernumerary arteries was parallel in thirteen $(86.6 \%)$ and crossing in two (13.3\%). There were bilateral supernumerary renal arteries in three bodies $(6 \%)$. All of these were hilar on the two sides except in one case which had bilateral lower polar supernumerary renal arteries (Figure 3).

In a body with a supernumerary renal artery on the right side, double ureters were found on the 
left side. In another case with SRA on the right side, there was an early bifurcating axillary artery on the ipsilateral side. Only in one cadaver, the renal artery entered the hilum of the left kidney anterior to the accompanying renal vein.

Imaging $(\mathrm{n}=150)$

The mean age of the study population was $23.28 \pm 15.5$. The study included 93 males $(62.5 \%)$ and 57 females (37.5\%).

The most common vertebral level of origin for the renal arteries was between the lower border of $\mathrm{L} 1$ vertebra and the upper border of $\mathrm{L} 2$ vertebra, on both the right (46\%) and left sides $(47.3 \%)$. The next level of origin was L2 in $(29.3 \%)$ on the right side, and it was $(27.3 \%)$ on the left side. Only 3.3\% of the cases showed the renal artery arising above L1 on both sides, and in $2.6 \%$ it arose below $\mathrm{L} 2$.

The most common branching site on the right side was prehilar in 69 subjects (46\%), followed by hilar in 47 subjects $(31.3 \%)$ and intraparenchymal in 34 subjects (22.6\%). Similarly, on the left side, the branching site was frequently pre-hilar in 84 subjects (56\%), hilar in 44 subjects $(29.3 \%)$ and intra-parenchymal in 22 subjects (14.6\%). Bifurcation of the artery was commoner than trifurcation. It was found in $84(72 \%)$ angiograms on the right side and in $91(71.1 \%)$ on the left side. The most common anatomical variation was the presence of a supernumerary renal artery which was detected in 40 subjects (26.6\%). In them, there were 47 SRA, 21 on the right side and 26 on the left side. Figures 6and 7 show SRA on the left and right sides respectively. Seven of the supernumerary arteries were superior polar, eight were hilar and thirty-two were inferior polar. The course was parallel in most of the cases.

SRA was found to be more common in males. Thirty males $(32.2 \%)$ had SRA, while ten females $(17.5 \%)$ showed this anatomical variation. All Supernumerary renal arteries originated from the abdominal aorta, except in a male with a pelvic kidney on the left side. It was supplied by three renal arteries, one of them arose from the left common iliac artery. In another two males there were triple renal arteries on the left side (Figure 8). No similar cases were found on the right side. Bilateral supernumerary renal arteries were detected in 6 subjects (4\%) (Figure 9). Vertebral level of origin for supernumerary renal arteries was commonly between L1 and L2. Next to the presence of SRA, the second most common anatomical variation was early bifurcation of the renal arteries. This was found in five subjects $(3.3 \%)$ on the right side and in two subjects (1.3\%) on the left side (Figure 10).

The overall results of anatomical variations in both groups $A \& B(n=200)$ :

There was a total of 62 SRA occurring in 51 subjects i.e. $25.5 \%$ of the cases. Bilateral supernumerary renal arteries were in nine of them $(4.5 \%)$. SRA were superior polar in 8 subjects (12.9\%), hilar in $18(29.03 \%)$ and inferior polar in 36 subjects $(58.05 \%)$. The difference in the frequency of the SRA between the cadaveric and the radiological studies was statistically non-significant on the right side ( $p$ value $=0.472$ ) as well as on the left side $(p=0.228)$. 
Anatomy Journal of Africa. 2018. Vol 7 (1): $1103-1112$

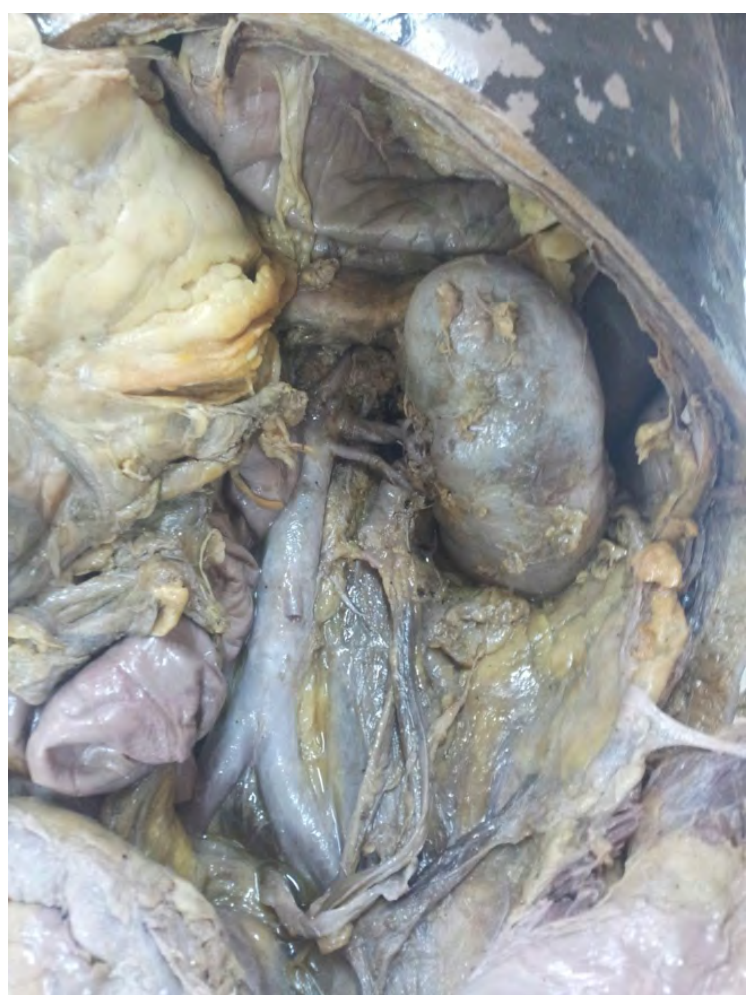

Fig.1: A supernumerary renal artery on the left side arising from the abdominal aorta.

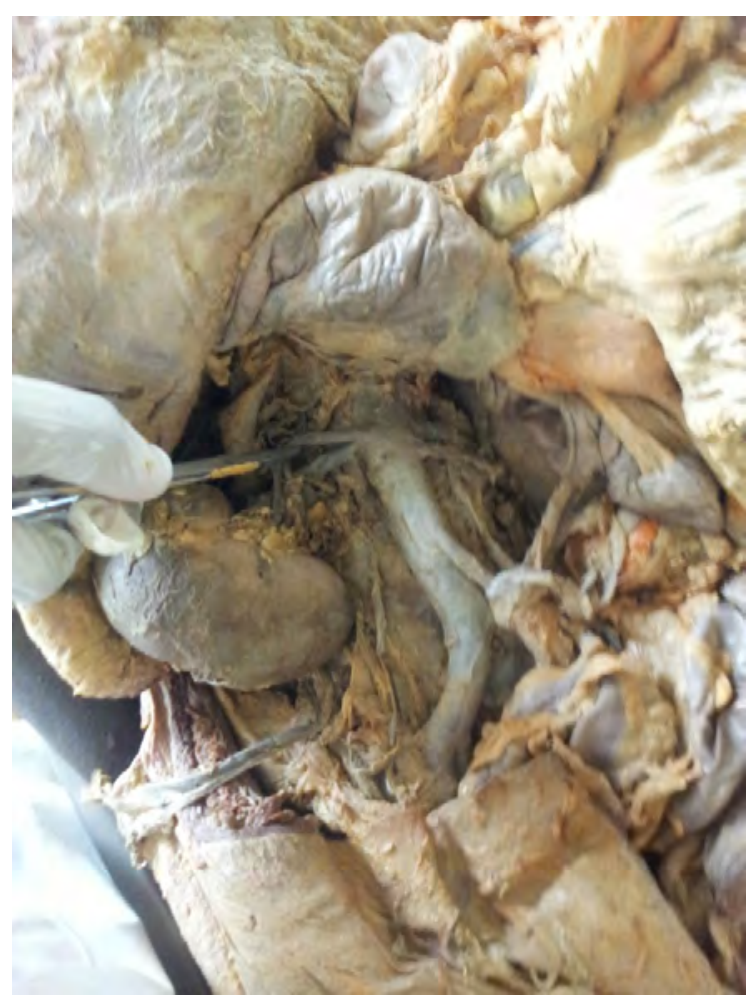

Fig 3: Bilateral SRA arising from the abdominal aorta.

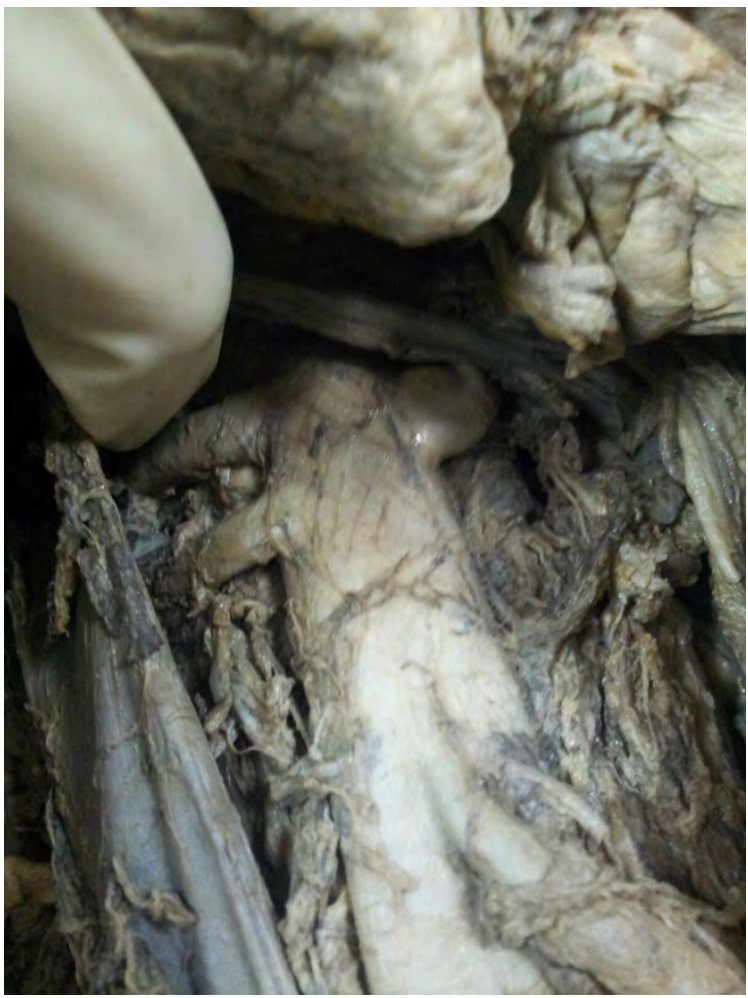

Fig 2: A supernumerary renal artery on the right side arising from the abdominal aorta.

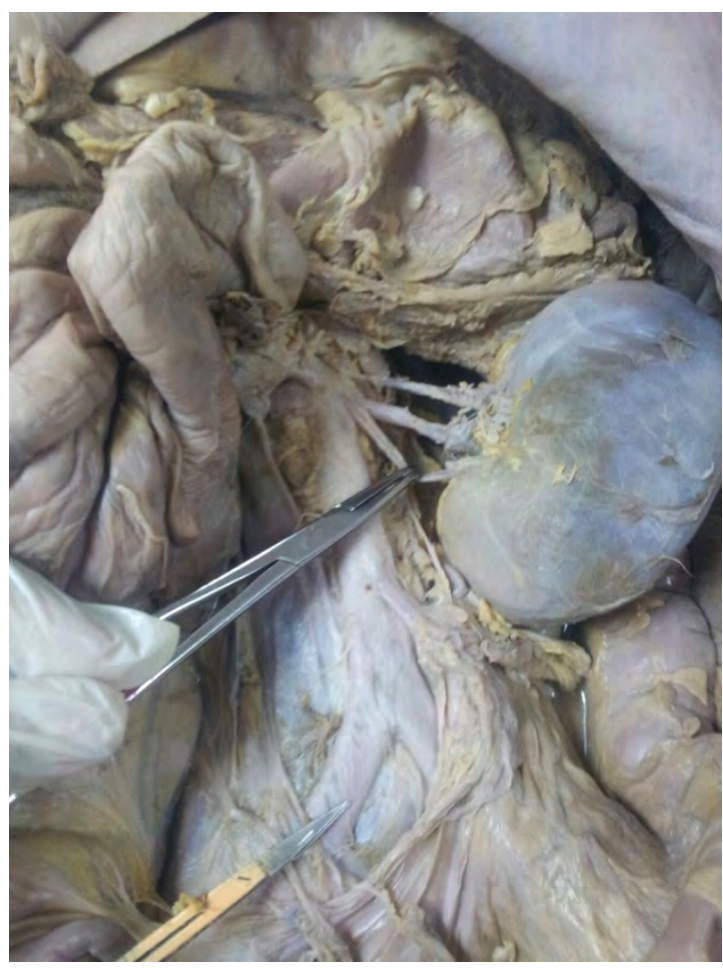

Fig 4: Three renal arteries were detected on the left side. Two arose from the lateral surface and one from the anterolateral surface of the aorta. All of them have entered the kidney through the hilum 
Anatomy Journal of Africa. 2018. Vol 7 (1): 1103 - 1112

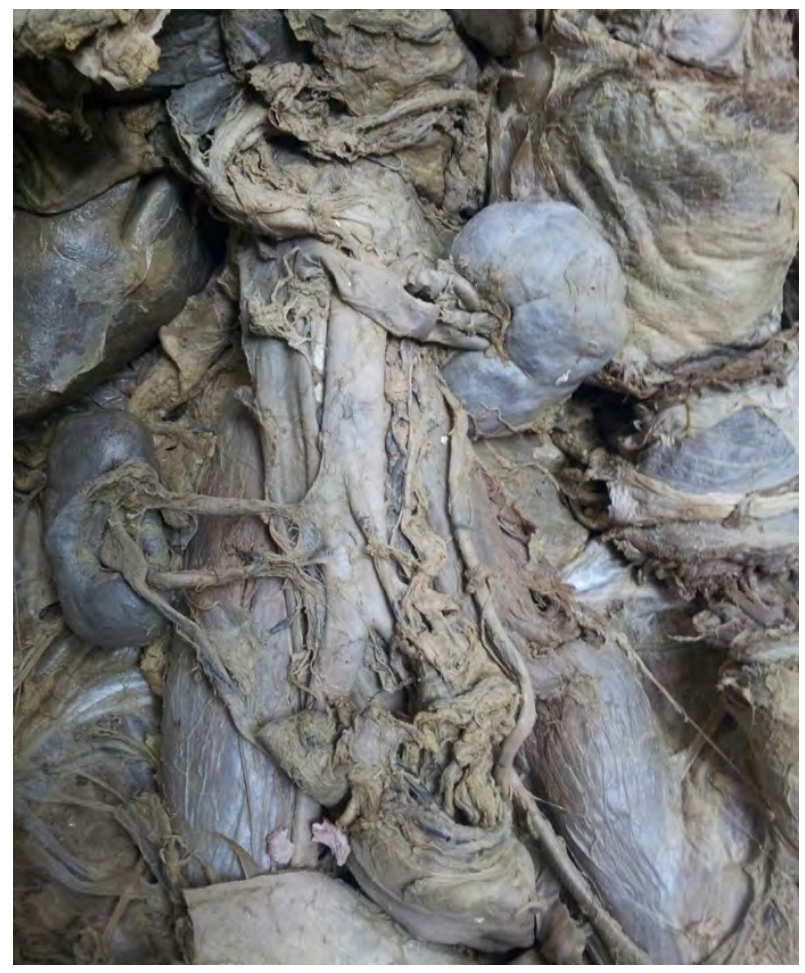

Fig 5: One cadaver with low lying kidney on the right side with two renal arteries arising from the aorta at the level of $\mathrm{L} 3$.

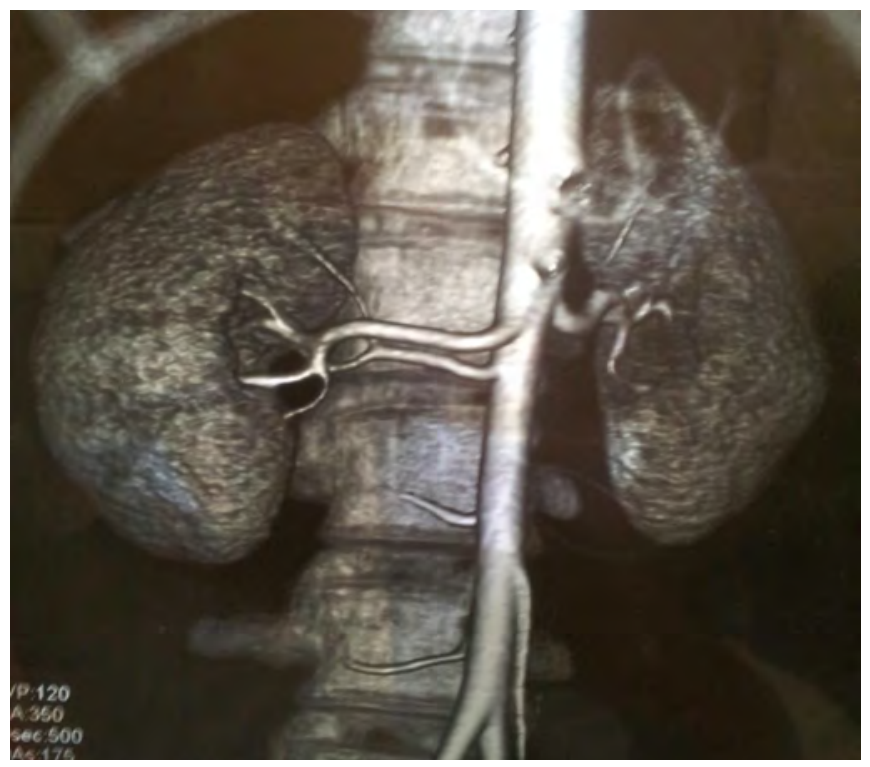

Fig 7: SRA on the right side.

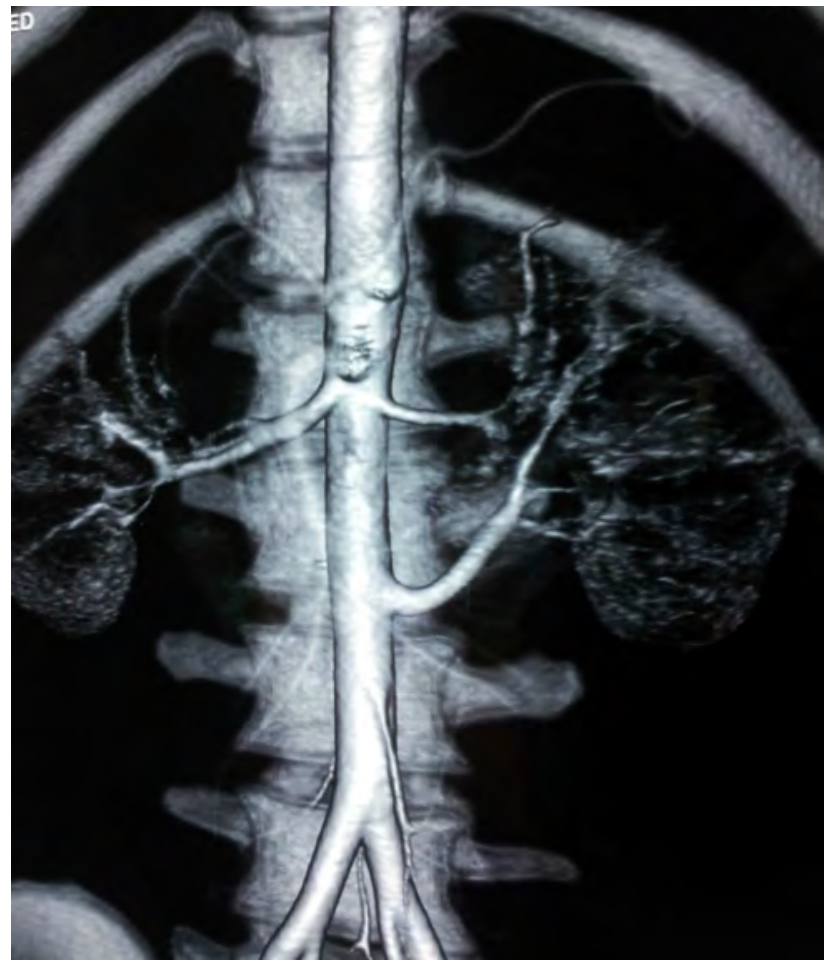

Fig 6: SRA on the left side arising from the aorta.

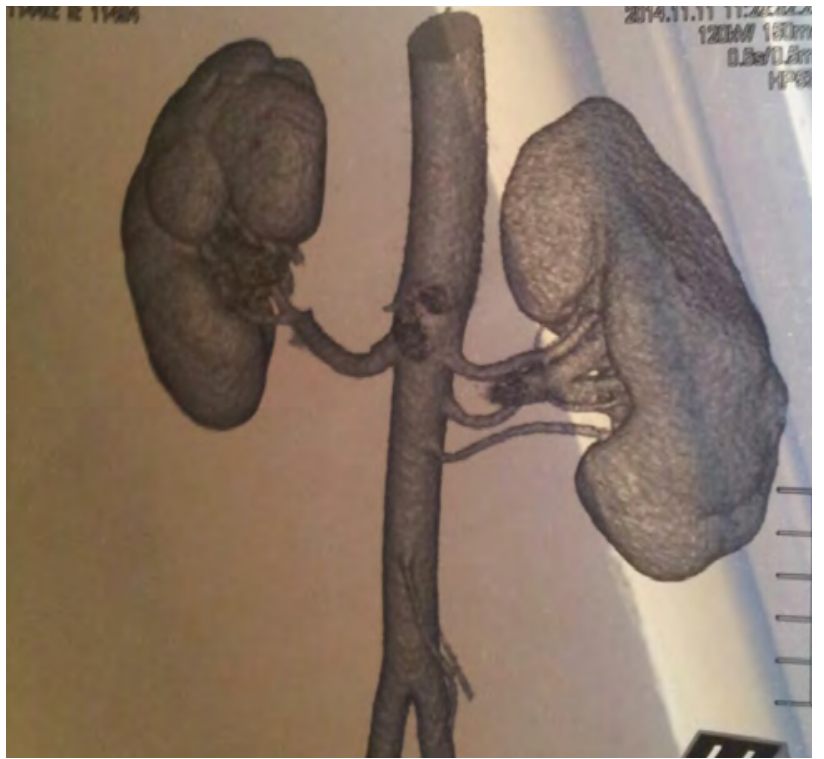

Fig 8: Three SRA arising from the abdominal aorta on the left side. 


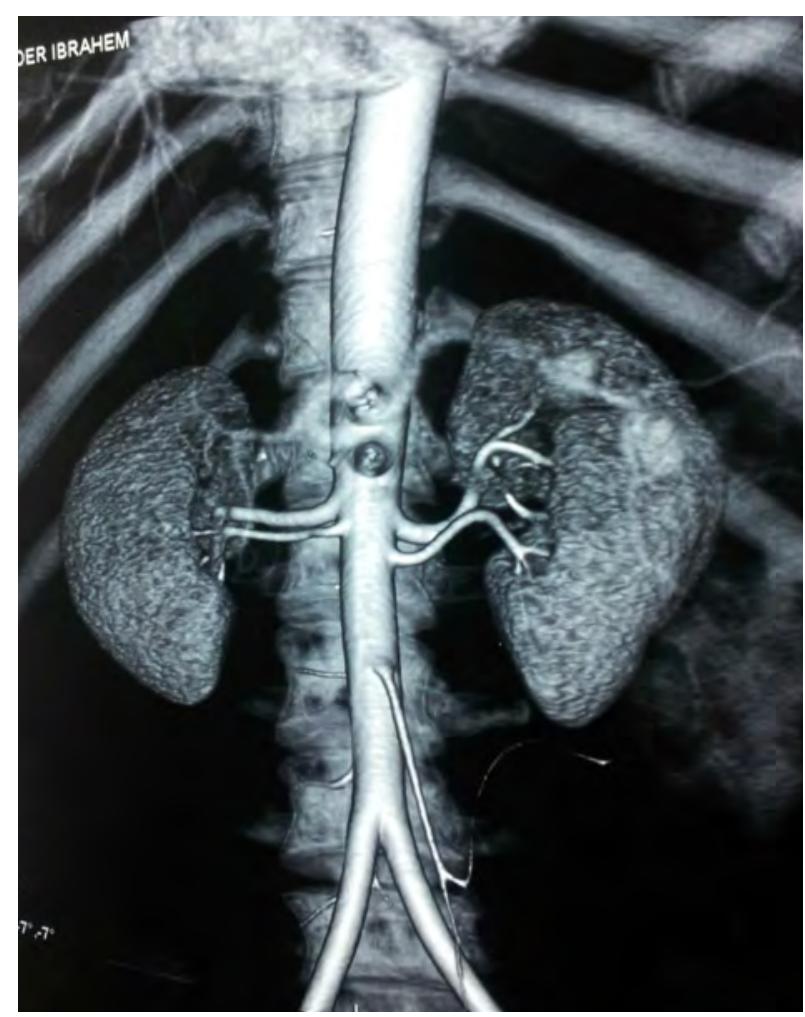

Fig 9: Bilateral supernumerary renal arteries. Most of them had a parallel course to the main renal arteries and they were inferior polar

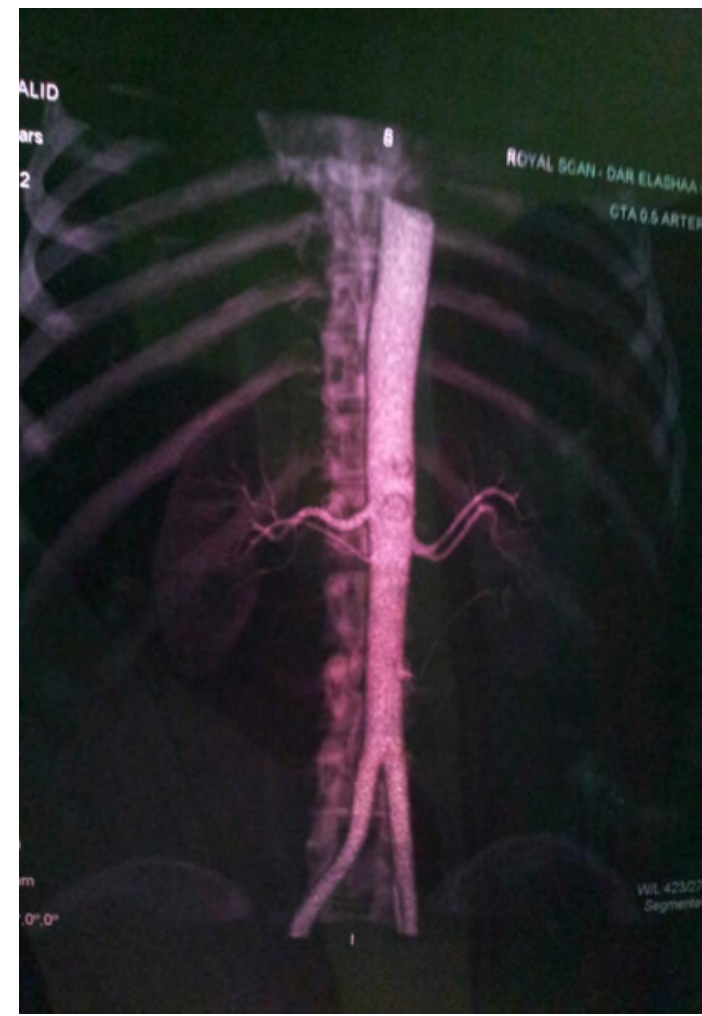

Fig 10: Early bifurcation of the renal artery on the left side and supernumerary renal artery on the riaht side.

Table 1: Comparison between the cadaveric and the radiological studies

\begin{tabular}{|l|l|l|l|l|}
\hline \multirow{2}{*}{ Result } & \multicolumn{2}{l|}{ Cadaveric study } & \multicolumn{2}{l|}{ Radiological study } \\
\cline { 2 - 5 } & Number & Percent & Number & Percent \\
\hline Total number of participants. & 50 & $100 \%$ & 150 & $100 \%$ \\
\hline Male participants. & 50 & $100 \%$ & 93 & $62.5 \%$ \\
\hline Female participants. & 0 & $0 \%$ & 57 & $37.5 \%$ \\
\hline Subjects with SRA. & 11 & $22 \%$ & 40 & $26.6 \%$ \\
\hline $\begin{array}{l}\text { Subjects withSRA on the right side } \\
\text { only*1. }\end{array}$ & 6 & $12 \%$ & 15 & $10 \%$ \\
\hline $\begin{array}{l}\text { Subjects with SRA on the left side } \\
\text { only*2. }\end{array}$ & 3 & $6 \%$ & 20 & $13.3 \%$ \\
\hline $\begin{array}{l}\text { Subjects with SRA on the both } \\
\text { sides. }\end{array}$ & 3 & $6 \%$ & 6 & $4 \%$ \\
\hline
\end{tabular}

$* 1$ P Value $=0.472$ (Statistically non-significant difference between the two studies.)

${ }^{* 2}$ PValue $=0.228$ (Statistically non-significant difference between the two studies.) 
Table 2: Comparison of the frequency and course of the SRA between cadaveric and the radiological studies.

\begin{tabular}{|l|l|l|l|l|}
\hline \multirow{2}{*}{ The result } & \multicolumn{2}{l|}{ The cadaveric study } & \multicolumn{2}{l|}{$\begin{array}{l}\text { The radiological } \\
\text { study }\end{array}$} \\
\cline { 2 - 5 } & Number & Percent & Number & Percent \\
\hline Total frequency of SRA. & 15 & $100 \%$ & 47 & $100 \%$ \\
\hline Frequency of SRA on the right side. & 9 & $60 \%$ & 21 & $44.6 \%$ \\
\hline Frequency of SRA on the left side. & 6 & $40 \%$ & 26 & $55.3 \%$ \\
\hline Origin of SRA from the aorta. & 15 & $100 \%$ & 46 & $97.8 \%$ \\
\hline Superior polar SRA. & 1 & $7.1 \%$ & 7 & $14.8 \%$ \\
\hline Inferior polar SRA. & 4 & $28.5 \%$ & 32 & $68.08 \%$ \\
\hline HilarSRA. & 10 & $64.4 \%$ & 8 & $17.02 \%$ \\
\hline SRA parallel to the renal artery. & 13 & $86.6 \%$ & 34 & $72.3 \%$ \\
\hline SRA crossing the renal artery. & 2 & $13.3 \%$ & 13 & $27.6 \%$ \\
\hline
\end{tabular}

\section{DISCUSSION}

Many cadaveric and radiological studies in the literature described the morphology and anatomical variations of the renal artery. The classic description of renal arterial anatomy is a single renal artery arising from the abdominal aorta between $\mathrm{L} 1$ and $\mathrm{L} 2$ emerging from the lateral surface of the aorta in most cases (Chummy,1999). However, the renal arteries present great variability in morphological expression regarding their emergence and ramification level (Saldarriaga et al.,2008). It may arise from the anterolateral surface in a significant percentage. The right renal artery can emerge at higher level than the left, and both arteries can be located at the same level (Saldarriaga et al., 2008; Vrinda and Ratnabali,2013). In the current study, origin of the renal artery commonly between L1 and L2 matches the results of many others (Hatice et al .,2012; Peter J et al .,2013; Tuncay et al .,2011; Uğur et al ., 2006).

Prehilar branching, being the predominant branching site in this study, agrees with the results of many authors (Rehmah et al .,2008; Tuncay et al .,2011; Virendra B et al ,2010), others however have reported hilar branching as being the commonest (Ogeng'o et al .,2010; Vrinda et al .,2013). This difference indicates great variability in the site of renal artery division and clinicians should be aware of it.

The dominance of renal artery bifurcation over trifurcation was similar to the results of Ogeng'o et al (2010) and the results of many other authors, giving a probable hint that bifurcation may be the predominant pattern in general.

In the present study the renal artery had a broad range of variability in its morphology regarding the origin, number, course and level of branching. Such aspects are important when considering a surgical approach to the kidney or imaging of the renal vasculature.

Literature illustrates that beside the renal artery, there can be SRA, with a different starting point, course and entry to the renal parenchyma. Different origins of renal arteries and frequent variations are explained by the development of the mesonephric arteries. These arteries form a vascular network feeding the kidneys, suprarenal glands, and gonads on both sides of the aorta between the $6^{\text {th }}$ cervical and the third lumbar vertebrae, a region of nine pairs of lateral mesonephric arteries arising from the dorsal aorta known as rete arteriosumurogenitale 
(Keibel and Mall, 1912). These are divided into three groups as follows: the $1^{\text {st }}$ and $2^{\text {nd }}$ arteries as the cranial group, the $3^{\text {rd }}$ to $5^{\text {th }}$ arteries as the middle group and $6^{\text {th }}$ to $9^{\text {th }}$ arteries as the caudal group. The middle group gives rise to renal arteries. Persistence of more than one renal arteries of the middle group results in multiple renal arteries (Keibel and Mall, 1912). Thus, the supernumerary renal arteries in this study, were a result of two persisting lateral mesonephric arteries from the middle group.

The fact that the SRA is the most common anatomical variation in this study, followed by early bifurcation, is similar to many other studies in the literature (Budhiraja et al., 2013; Elvira et al., 2007; Shoja et al .,2008). Early bifurcation of the renal artery is considered to be equivalent to arterial supply by multiple arteries, both being contraindications for laparoscopic nephrectomy and both must be considered when performing a transplant (Sampaio and Passos, 1992). Transplantation of kidneys that have one renal artery is technically easier and the rate of complication and kidney loss are lower compared to transplantation of kidneys with more than one renal artery (Sampaio and Passos, 1992).

Some factors (eg: genetic backgrounds, oxygenation and hemodynamic changes) andsome diseases like galactosemia, may account for the presence of SRA (Mizoguchi et al., 2012). The absence of participant's medical history in the present study makes the confirmation of such possibilities difficult.

Absence of significant difference in the frequency of SRA between the cadaveric and radiological studies is expected because both of them were done in a similar population i.e. the Sudanese subjects. The results were close to the figures of Uğur et al (2006) who found SRA in $24 \%$, as well as to the results of Johnson et al (Peter et al .,2013)who found it in $23.5 \%$. On the other hand, other studies have reported higher frequencies (Ogeng'o et al.,2010; Peter et al., 2013), and this confirms a substantial evidence that the frequency of supernumerary renal arteries varies between populations.
The predominance of the SRA in males goes with the results of Gümüş et al (2012).There is a clear discrepancy in the origin of the SRA between the cadaveric and the radiological studies. In the first study it was more common on the right side, while in the second, it was more on the left. This discrepancy was also reported in the literature (Budhiraja et al., 2013;).

The origin of the supernumerary renal artery most commonly from the abdominal aorta at the level between L1 and L2 segments, is in line with many of the literature studies (Peter et al .2013).

Lower polar and hilar supernumerary renal arteries were more common in this study, passing parallel to the main renal artery. These results are comparable to those reported by other Ogeng'o et al., (2010) and Virendra et al (2010) among Kenyans and Budhiraja et al (2013) in Indians. They were also in agreement with studies reported from Bosnia (Elvira T et al., 2007) and Caribbean areas (Peter B J et al ., 2013). It is important for the surgeons to know if the SRA is supplying the upper or lower poles because their accidental injury during surgery can lead to necrosis. So, any disease confined to the upper or lower poles of the kidney will need special care in case of additional vessels supplying these regions. Moreover, Inferior polar supernumerary renal arteries are more important clinically because they can lead to obstruction of the pelvi-ureteric junction (Shoja et al., 2008).

Bilateral supernumerary renal arteries were uncommon and were detected in about five percent of the entire sample. Ankolekar et al (2013) reported a close percentage of $6.67 \%$, while others reported higher figures (Peter et al ,2013).

Triple renal arteries were present in four cases only in this series (2\%), and were all on the left side, this is similar to what has been reported by Ogeng'o et al (2010). The association between the variations of the renal artery and other anatomical variations, which was found in the current study, has been also described in the 
literature (Kayalvizhi et al., 2011; Necdet et al .2005; Tuncay et al ., 2011).

In conclusion, the kidney is usually vascularized by one renal artery. Variations of the renal artery are not uncommon; they should be kept in mind during interventional procedures. The most common anatomical variation of the renal artery was the presence of a supernumerary renal artery which was found in $25.5 \%$ of the cases. This was followed by early prehilar bifurcation which was present in $6.5 \%$ of the cases.

Conflict of interest: Both authors of the paper have no conflict of interest. The research was not funded.

\section{REFERENCES}

1. Alp B, Deniz D, Kadriye ME. 2003. Bilateral additional renal arteries and an additional right renal vein associated with unrotated kidneys. Saudi Medical Journal 24:5.

2. Beradinelli L. 2005. Technical problems in living donor transplantation. Transplant proc. 37: 2449 - 50.

3. Budhiraja V, Rastogi R, Jain V. 2013. Anatomical variations of renal artery and its clinical correlations: a cadaveric study from central India. J Morphol Sci. 30: 228-233.

4. Chummy S. 1999. The Abdomen. In regional and applied Last's Anatomy, $10^{\mathrm{TH}}$ edition. CHURCHILL LIVINGSTONE. pp 268-269.

5. Elvira T, AmelaK, Alma V, Eldan K. 2007. Review of the supernumerary renal arteries by dissection method. Acta Medica Academica 36: 59 - 69.

6. Hatice G, Yaşar B et al.2012. Variations of Renal Artery in 820 Patients Using 64-Detector CTAngiography. Clinical Study 34:286-290.

7. Kayalvizhi I, Monisha B, Usha D. 2011. Accessory left testicular artery in association with double renal vessels: a rare anomaly. Folia Morphol70:309-311.

8. Keibel F, Mall FP.1912.Manual of human embryology. LIPPINCOTT.

9. Mizoguchi N, Sakura N, Ono H, Naito K, Hamakawa M .2001. Congenital porto-left renal venous shunt as a cause of galactosemia. J Inherit Metab Dis 24:72-78.

10. Nayak S. 2007.Abnormal course of right renal artery and ovarian vessels: A Case Report. The Internet Journal of Biological Anthropology2: 15.

11. Necdet K, Bülent Y, Cenk K, Yalçın K, Hasan 0.2005.Accessory renal arteries and an anomalous testicular artery of high origin. Gulhane Med J 47: 141-143.

12. Ogeng'oJA, Charles OM, Simeon RS, John stone MM, Acleus KM .2010. Variant anatomy of renal arteries in a Kenyan population. Ann Transplant15: 40-45.

13. Peter B J, Shamir OC, Sundeep DS et al .2013. Accessory renal arteries in a Caribbean population: a computed tomography-based study. Springer Plus 2:443.

14. Rehmah S, Mohammad T, WaqasS. 2008. The variations in the presegmental arterial pattern of human kidneys.Ann Pak Inst Med Sci 4: 212-215.

15. Saldarriaga B, Pinto SA, Ballesteros LE. 2008. Morphological expression of the renal artery: a direct anatomical study in a Colombian half-caste population. Int J Morphol26:31-38.

16. Sampaio F J, Passos MA. 1992. Renal arteries: Anatomic study for surgical and radiological practice. SurgRadiol Anat14:113-7.

17. Satyapal KS, Haffjee AA, Singh B, Ramsaroop L, Robbs JV, Kalideen JM .2001. Additional renal arteries: incidence and morphometry. Surg Radio Anat 23:33-8.

18. Shoja MM, Tubbs RS, Shakeri A.2008.Peri-hilar branching patterns and morphologies of the renal artery: a review and anatomical study. Surg Radiol Anat 30:375-382. 
19. Tuncay H I, Meryem Ö, Barış T, Ali DK, Berna SO, Murat C. 2011. CT angiography of the renal arteries and veins: normal anatomy and variants. Diagn Interv Radiol17:67-73.

20. Uğur Ö, Levent O, Fahri T, Osman K, Zafer K, NihalK. 2006. Renal artery origins and variations: angiographic evaluation of 855 consecutive patients. Diagn Interv Radiol 12:183-186.

21. Virendra B, Rakhi R, Asthana AK. 2010. Renal artery variations: embryological basis and surgical correlation. Romanian Journal of Morphology and Embryology51:533-536.

22. Vrinda A, Ratnabali S. 2013. Renal artery variations: a cadaveric study with clinical relevance.IJCRR5: 154-161. 